\title{
INDUSTRIA CULTURAL, CRÍTICA Y CREACIÓN ARTÍSTICA: LA PERSPECTIVA DE ADORNO EN TORNO A LA PRODUCCIÓN CULTURAL Carlos Garduño Comparán*
}

RESUMEN: En el presente texto se intenta mostrar la perspectiva de Theodor Adorno en relación a la producción cultural, desde tres aspectos fundamentales de su filosofía. Se partirá, en primera instancia, de su crítica a la "industria cultural", la cual es caracterizada como un orden de producción en el que los criterios se basan en lo meramente comercial y en el que la cultura pierde cualquier tipo autenticidad y legitimidad. Posteriormente, se analizarán las propuestas de opciones auténticas de cultura, tanto en la crítica cultural, como en la creación artística.

PALABRAS CLAVE: Industria cultural, crítica cultural, producción cultural, creación artística, teoría crítica.
ABSTRACT: This work illustrates Theodor Adorno's perspective regarding cultural production from the point of view of three of his fundamental aspects in his philosophy. First, we will delve into his criticism of cultural industry, which is characterized as a production line whose criteria is solely based on commercialism and in which culture loses its authenticity and legitimacy. Then, his suggestions for authentic options of culture, in cultural criticism as well as in artistic expression, will be assessed.

KEYWORDS: Cultural Industry, cultural criticism, cultural production, artistic expression, critical theory.

* Departamento Académico de Estudios Generales, ITAM. 
INDUSTRIA CULTURAL, CRÍTICA Y CREACIÓN ARTÍSTICA: LA PERSPECTIVA DE ADORNO EN TORNO A LA PRODUCCIÓN CULTURAL

Ha llegado a ser obvio que ya no es obvio nada que tenga que ver con el arte, ni en él mismo, ni en su relación con el todo, ni siquiera su derecho a la vida. Th. W. Adorno, Teoría Estética.

La situación cultural en la época del capitalismo de consumo, debido a su capacidad de reproducción técnica y a la extremada especialización, ha generado, para Th. Adorno, un tipo de producción cultural que se caracteriza por marcar toda creación con un rasgo de semejanza, cuyo criterio se subordina al sistema económico. El poder del capital se impone sobre cualquier tipo de expresión, sometiéndola a una lógica ajena a los intereses auténticos de los individuos, quienes se deben conformar con el entretenimiento que les pueden brindar. En tal tipo de cultura, todo se reduce a una dinámica mercantil entre productores y consumidores, limitando la calidad del objeto cultural a la de un mero medio de reproducción del sistema económico. Podemos decir que la cultura, dominada por los intereses económicos del capitalista, ejerce una violencia sobre la capacidad de generar productos culturales originales que respondan a las verdaderas necesidades expresivas, materiales y objetivas de los individuos. El propósito de este texto es mostrar la manera en que funciona para Adorno la mencionada "industria cultural" del capitalismo de consumo, así como exponer las propuestas de este pensador para hacer frente a dicha situación desde la limitada posición del crítico cultural y la del artista, la cual resulta ser mucho más relevante en tanto que es capaz de producir los objetos que se opongan materialmente a la violencia de la reproduc- 
ción masiva de entretenimientos vacíos de verdadero contenido significativo, para finalizar con mis propias conclusiones y opiniones.

Así pues, preguntémonos ¿cómo funciona la industria cultural? ¿Por medio de qué cauces el capitalismo impone sus representaciones y su ideología? ¿En qué consiste la violencia de esta pseudo-cultura? La violencia que Adorno intenta mostrarnos con el concepto de industria cultural es cualitativamente distinta de aquella represión física y brutal que se basa en la agresión directa y el miedo que provoca. Me parece que sería difícil hablar de agresión aquí, y sin embargo, podemos hablar de violencia. Lo que se muestra es cómo el funcionamiento de un sistema primordialmente económico ejerce en los individuos un tipo de represión que impide fundamentalmente su libre desarrollo cultural, bajo la amenaza, no proferida sino implícita en el mismo funcionamiento del sistema, de quedar relegados de toda actividad social por la imposibilidad de acceder a los recursos materiales necesarios. La lógica de la industria cultural es simple:

Su poder se refuerza cuanto más brutalmente se declara. El cine y la radio no necesitan ya darse como arte. La verdad de que no son sino negocio les sirve de ideología que debe legitimar la porquería que producen deliberadamente. ${ }^{1}$

Puesto que los encargados de decidir qué se produce culturalmente son a la vez los propietarios de los medios de reproducción, cuyo capital depende del funcionamiento del sistema económico, los objetos culturales creados responderán exclusivamente a fines mercantiles, olvidándose por completo de su calidad. Con ello, no podemos hablar más de arte de alto rango ni de arte popular, pues ambos son equiparados a los ojos del capitalista; son igualmente valiosos si generan ganancia. Así, "la técnica de la industria cultural ha llevado sólo a la estandarización y producción en serie y ha sacrificado aquello por lo cual la lógica de la obra se diferenciaba de la lógica del sistema social". ${ }^{2}$ La violencia de tal uso de la técnica, pues, radica en la anulación de la particularidad y originalidad de las obras, generando con ello la represión de la creatividad de los individuos; lo que éstos puedan producir queda limitado por las determinaciones del mercado. Cualquier manifestación particular que pudiera alejarse del sistema es acallada por la exigencia del estereotipo, cuya máscara es un tipo de especialización que ignora toda la

${ }^{1}$ Theodor Adorno, "La industria cultural", en Dialéctica de la ilustración, 1998, Madrid, Trotta, p. 166.

${ }^{2}$ Ibid. 
NOTAS

tradición artística, sus estilos y su utilización técnica de materiales, lo cual pierde importancia completamente pues no importa lo que se produzca mientras reproduzca el sistema.

La justificación del capitalista es que el mercado demanda dichos productos, con lo que "el recurso a los deseos espontáneos del público se convierte en un fútil pretexto". ${ }^{3}$ Sin embargo, para Adorno, eso es precisamente la clave del engaño de masas. Cuando se produce lo que el público desea, en forma de entretenimiento y no de satisfactor real, eso sólo significa que el público no puede cumplir por sí mismo dichas aspiraciones, las cuales se le dan en forma de representación de lo que socialmente podría alcanzar si la suerte, calculada por el sistema, así lo decide. En otras palabras, lo que se produce y reproduce hasta el hastío son las mismas fórmulas fantasmagóricas de éxito, una y otra vez, sin violar jamás su lógica de funcionamiento. El deseo del espectador queda así atrapado en los objetos estereotipados de siempre; fijado, en términos psicoanalíticos, a un objeto convertido en fetiche por la fantasía, del cual sólo puede obtener "placer previo", es decir, excitación y pequeños placebos como los efectos risueños que provocan la ligereza, "la naturalidad" de las representaciones producidas -que

${ }^{3}$ Ibid, p. 167. ni siquiera aspiran a la liberación explosiva de energía que Freud identificó en el efecto de los buenos chistes capaces de evadir la censura-. El arte, pues, es despojado de su capacidad de sublimación. Sublimar es sustituir por medios culturales lo que no se pudo obtener como satisfactor de otra manera. Lograrlo implica una tensión entre la lógica interna de la obra y el medio circundante que impedía el goce, entre lo particular y lo universal que el estilo del auténtico objeto artístico -en la concepción de Adorno- manifiesta. En la industria cultural, sin embargo, "no se llega ya a ninguna tensión entre los polos: los extremos que se tocan quedan diluídos en una confusa identidad, lo universal puede sustituir lo particular, y viceversa" ${ }^{4}$ La lógica de la industria cultural impide que los productores sean capaces de crear sus propios satisfactores, otorgándoles en su lugar la ilusión del éxito dentro del sistema, cuya cara oculta es la segregación en caso de negarse a ser parte de su funcionamiento. Así, "la diversión es la prolongación del trabajo bajo el capitalismo tardío"; 5 el sujeto "ya no puede experimentar otra cosa que las copias o reproducciones del mismo proceso de trabajo", con lo cual "el placer se petrifica en aburrimiento". ${ }^{6}$

\footnotetext{
${ }^{4} I b i d$, p. 174.

${ }^{5}$ Ibid, p. 181.

${ }^{6}$ Ibid.
} 
Evidentemente, Adorno no considera que las producciones de la industria cultural se puedan tomar en serio; es decir, para él eso no puede ni siquiera ser considerado como cultura. Por ello, sus concepciones de crítica cultural y de arte nos pueden orientar en torno a las posibilidades de una cultura capaz de producir, más allá de la industria de consumo, objetos culturales que realmente produzcan lo que se espera de ellos. Y, ante esto, la pregunta obligada es ¿qué esperamos de un crítico de la cultura y de un artista? ¿Por qué lo que crean es importante para la producción de una auténtica cultura y cómo ello contribuye a oponerse a la violencia del sistema económico predominante, cuya lógica cultural nos mantiene en el vicio de la repetición y el tedio?

Por principio de cuentas, me parece que podemos ubicar tanto al crítico como al artista en una posición privilegiada con respecto a la cultura, pero a la vez inútil, en términos ideológicos y económicos. ¿Por qué? Porque su labor los coloca en un lugar en el que no tienen que responder a las exigencias de los modelos dominantes, aun cuando sean ellos quienes posibiliten su labor; porque su trabajo consiste precisamente en no aceptar lo dado, aunque sea a partir de lo dado que puedan existir. En el caso del crítico, esto se cumple desde el análisis de la cultura y de la argumentación a favor o en contra de cualquier manifestación. En el caso del artista, desde la producción material de nuevos objetos cuya introducción en la dinámica cultural es capaz de modificar su lógica.

Con respecto al crítico, citemos la opinión del propio Adorno sobre su función:

Al crítico cultural no le sienta la cultura, pues lo único que debe a ésta es la desazón que le procura. El crítico cultural habla como si fuera representante de una intacta naturaleza o de un superior estado histórico; sin embargo, él mismo participa necesariamente de esa entidad por encima de la cual se imagina egregiamente levantado. ${ }^{7}$

El crítico cultural, a pesar de que su labor se basa precisamente en la cultura, se distingue de los especialistas de la industria en que no tiene por qué seguir su misma lógica para contribuir a la cultura. Su contribución se puede medir en la medida de su alejamiento de ella: "Lo que hace el crítico es articular la diferencia o distancia en el mismo dispositivo cultural que pretendía superar y que precisamente necesita de esa distancia para tomarse por cultura". ${ }^{8}$ Pero,

${ }^{7}$ Theodor Adorno, "La crítica de la cultura y la sociedad", en Prismas. La crítica de la cultura y la sociedad, 1962, Barcelona, Ariel, p. 9.

${ }^{8} \mathrm{Ibid}, \mathrm{p} .10$. 
NOTAS

¿por qué es necesaria la distancia como condición para que algo se pueda "tomar por cultura"? Porque, contrariamente a lo que sucede en la industria cultural, entre las creaciones culturales y la realidad de la que surgieron, se debería dar una diferencia en la cual pueda ser identificable tanto su particularidad como su contribución. Al articular dichas distancias, el crítico es capaz no sólo de cuestionar la dignidad de la cultura, sino que escapa a su legitimación; es decir, la cultura, a los ojos del crítico, nunca tendría ganado el derecho a ser considerada como legítima por sí misma, sino por lo que introduce en la realidad material. El crítico, pues, no debería ser un mero informador de lo que pasa en la cultura y mucho menos un manifestante de la fe en la cultura como tal -es decir, en su versión oficial-; eso es más bien publicidad y un mecanismo al que recurre la industria. $\mathrm{Su}$ papel tan sólo se puede entender dialécticamente:

La cultura no es verdadera más que en sentido crítico-implícito, y el espíritu, cuando lo olvida, se venga de sí mismo en los críticos que él mismo cría. La crítica es un elemento inalienable de la cultura, en sí misma contradictoria; y con toda su inveracidad es la crítica tan verdadera como la cultura es falaz. ${ }^{9}$

${ }^{9} \mathrm{Ibid}, \mathrm{p} .13$.
La relación, pues, de la crítica con la cultura no se puede entender más que en función de oposiciones; es un cúmulo cuyo fruto no puede ser su separación radical, ya que una no se da sin la otra, sino el movimiento mismo de la cultura, en cuya esencia está el negarse a fijarse en valores ahistóricos. El esfuerzo del crítico es de constante valoración de la autenticidad de lo producido; una autenticidad jamás asegurada, pues el crítico no puede dejar de valorar desde la cultura a la que critica y el objeto no puede permanecer en las categorías de la autenticidad inmutable sin convertirse en fetiche. El trabajo del crítico se basa en una insistencia en la independencia y autonomía de las obras respecto a los fines de la sociedad y en una "ambigua promesa de la cultura mientras la existencia de ésta depende de la realidad vanamente conjurada". ${ }^{10}$ La esencia de la crítica está en la dialéctica entre una promesa de cultura-que nunca debería ser aceptada por completo-, la realidad criticada y la posibilidad objetiva de superación. Por ello, la crítica misma nunca está segura como tal y puede caer en cualquier momento en la ideologización. Sin embargo, su inestabilidad y su negatividad la vuelven un obvio instrumento de la cultura contra la violencia de su cosificación y reproducción. Mientras haya crítica, me

${ }^{10} \mathrm{Ibid}$, p. 15. 
parece, la industria cultural no podría mantenerse absolutamente estable e impenetrable, porque ella introduce conflictos en la lógica discursiva del sistema; porque descubre todas las mediaciones que constituyen al todo y muestra lo problemático de dichas relaciones. En este sentido, Adorno habla de una fisiognómica social: "Cuanto más alienado, socialmente mediado, filtrado, se hace el todo de los elementos naturales, cuanto más 'conciencia' es, tanto más se hace el todo "cultura". ${ }^{11}$ En todo momento se destaca el concepto de negatividad de la cultura como condición de su verdad en función de sus insuficiencias, las cuales la crítica no atribuye a diversos chivos expiatorios individuales, "sino que intenta derivarlas de los diversos momentos del objeto. Esta crítica persigue las aporías de la lógica, las irresolubilidades ínsitas ya en su tarea. Y en estas antinomias comprende las propiamente sociales". ${ }^{12}$

Ahora bien, a pesar de la disección de la situación cultural que pueda realizar el crítico, de su inconformidad ante lo dado y de la inestabilidad que pueda introducir su discurso, ello no basta para completar el movimiento de la cultura. Es necesario, también, crear objetos que respondan al dinamismo cultural. Objetos

${ }^{11} I b i d$, p. 24.

${ }^{12} \mathrm{Ibid}$, p. 26. que, contra la producción industrial de entretenimientos, ofrezcan una alternativa auténtica de cultura. Aquí el artista juega el papel central de la transformación cultural. ¿Qué es, pues, lo que hace el artista? Para empezar, se aleja de la producción estereotipada y del pensamiento en fórmulas rígidas y esquemáticas. Por otro lado, su trabajo refleja una insistencia en la inmanencia formal de la obra de arte más que en la idea de arte -como sucedía con el crítico-. Lo suyo, pues, es el objeto que produce en su materialidad; Adorno habla incluso de una "disciplina objetiva". ${ }^{13} \mathrm{El}$ artista conoce de arte como un métier. No persigue la promesa de cultura del crítico sino que parte de la comprensión de un oficio y de las posibilidades expresivas de la obra, en la cual es posible manifestar al hombre entero, pleno, indiviso, "hombre cuyos modos de reacción y cuyas capacidades no han sido disociadas ellas mismas según el esquema de la división social del trabajo, enajenadas las unas de las otras, cuajadas en funciones utilizables". ${ }^{14} \mathrm{El}$ artista tiene al arte en una alta opinión; no

${ }^{13}$ Theodor Adorno, "El artista como lugarteniente", en Crítica cultural y sociedad, 1973, Barcelona, Ariel, p. 191.

${ }^{14}$ Dicho concepto de arte y de expresión del hombre en su integridad es enunciado a partir de los pensamientos y creaciones de Paul Valéry, artista que para Adorno es un ejemplo paradigmático, ibid, p. 193. 
NOTAS

es una mercancía más sino algo por lo que vale la pena trabajar, un producto cuya técnica hay que llevar a la perfección. Precisamente esa aspiración a la perfección aleja al objeto artístico del resto de los objetos; incluso lo aleja del mismo artista, pues su deseo de perfección jamás se encontrará satisfecho. El artista, pues, es un productor excepcional, no por su personalidad, sino por los objetos que produce; el arte, para Adorno, está en el producto, no en su proceso ni en la vivencia o ideas del o sobre el artista:

al artista no "pertenece" sino lo mínimo de sus formaciones; que en verdad el proceso artístico de producción[...] tiene la rigurosa forma de una legalidad impuesta por la cosa, y que frente a esto la cantada libertad creadora del artista no tiene apenas peso. ${ }^{15}$

Los objetos artísticos, por su capacidad de expresión de lo humano en su totalidad no alienada por la producción industrial, están en representación de aquello que podríamos ser, transforman materialmente la cultura. En este sentido, el objeto artístico aspira a la autonomía, siempre en dialéctica con la sociedad. El arte, pues, no tiene una existencia asegurada; no es más que una posibilidad en el desarrollo de la historia. Por crear su esencia

${ }^{15}$ Ibid, p. 197. propia, las obras salen de la realidad empírica y se contraponen a ella como si crearan otro mundo. Así pues, "el arte se niega a ser definido". ${ }^{16} \mathrm{Se}$ puede decir que el trabajo artístico es la creación de realidades objetivas que no se pueden definir más que por su relación con aquello que no son. Esta negatividad se opone radicalmente a la homogeneidad de la producción cultural estereotipada, en la cual no es posible identificar la diferencia del objeto con el resto de la realidad. El arte, básicamente, es una cosa que se opone en su materialidad al resto de las cosas. Y por realidad, no sólo entenderemos la realidad social, sino la realidad psíquica interior. Aun cuando, para Adorno, la constitución del territorio del arte "está en correspondencia con la de un territorio interior de los seres humanos en tanto que espacio de su representación", ${ }^{17}$ lo cual posibilita la sublimación y el alejamiento de la realidad fáctica, esto no significa un acercamiento desmesurado ni al mundo de la fantasía ni al de la ficción. No se habla aquí de una subjetividad emocional, como en Freud, sino de una función crítica del objeto sobre los sujetos en sus relaciones sociales. La importancia del arte la debemos encontrar más bien en su praxis, opuesta a las otras prácticas socialmente dominantes

${ }^{16}$ Theodor Adorno, Teoría estética, 2004, Madrid, Akal, p. 10.

${ }^{17} \mathrm{Ibid}$, p. 18. 
como las de la producción, el trabajo y el consumo. No se trata, pues, de crear objetos para el deseo. El arte más bien se ubica entre el interés y el desinterés, sin poder definirse a partir de uno de ellos:

Conserva la negatividad de la realidad y toma posición respecto a ella, se modifica entonces el concepto del desinterés. Las obras de arte implican en sí mismas una relación entre el interés y la renuncia al mismo, en contra de la interpretación kantiana y de la freudiana. La misma contemplación de las obras de arte, separada forzosamente de objetivos de acción, se experimenta a sí misma como interrupción de la praxis inmediata y por ello como algo práctico en sí mismo, al estar resistiendo a la participación activa. ${ }^{18}$

La obra de arte funciona como una oposición a las razones e intereses del mundo, y como tal, se niega a aceptar lo dado, la normalidad (la infelicidad normal); de ahí su carácter creativo. Subjetivamente, se podría decir que subvierte al superyo; rompe su compromiso con él, pero a la vez lo utiliza como su propia herramienta creativa. La instancia prohibitoria, por lo tanto, no se elimina, sino que es usada en beneficio del deseo, más allá de la mera satisfacción:

La fuerza de la negatividad en la obra de arte es la que mide el abismo ${ }^{18}$ Ibid, p. 24. entre la praxis y la felicidad [...] La experiencia artística sólo es autónoma cuando rechaza el paladeo y el goce. El camino hacia ello atraviesa el hito del desinterés; la emancipación del arte respecto de los productos de la cocina y la pornografía es irrevocable. Pero no queda tranquila en el mero desinterés, porque esta etapa sigue reproduciendo, aunque modificando, el interés [...] A causa de la felicidad se renuncia a la felicidad. Así sobrevive el deseo en el arte. ${ }^{19}$

El artista, pues, no satisface ni nos promete satisfacciones. Se opone en ello a la hipocresía de la industria cultural y se contenta con hacer de su oficio una búsqueda de perfección jamás realizada que, en su dinámica creativa, crea más y nuevas manifestaciones culturales. Prefiere la autonomía y la resistencia por medio de la no-definición, con lo que pretende escapar de la violencia que homogeniza.

La obra de Adorno identifica claramente la tendencia violenta hacia la que la reproducción técnica, bajo el régimen del capitalismo de consumo, nos lleva en términos culturales. En esa dinámica, el concepto de cultura es degradado al ínfimo nivel de mercancía, de fetiche, de fijación, de entretenimiento que, a fuerza de repetirse, únicamente es capaz de llevarnos al tedio; que ni siquiera es capaz de

${ }^{19}$ Ibidem. 
NOTAS

generar una distinción entre el tiempo del trabajo y el del ocio, sino que reproduce de igual manera todas las facetas de la existencia. Me parece que Adorno nos propone, mediante sus conceptos de crítica cultural y de producción artística, dar un repaso a la historia de la producción cultural para darnos cuenta del terrible empobrecimiento en el que hemos caído, así como para intentar retomar la riqueza de lo que creemos - bajo la ideología dominante- superado, sin dejarnos llevar por nostalgias sin sentido, mistificando otras épocas como si pudiéramos traerlas de vuelta, sino generando consciencia sobre el trabajo que significa generar cultura, con el fin de continuar dicha historia. Para ello, es necesario oponerse al presente, a la violencia de una seudocultura que pretende detener la historia en una conformidad forzada, como si no existiera la posibilidad de concebir nuevos mundos, no sólo en la imaginación, sino en la realidad concreta, objetiva y material, pues, si la cultura no es material y no es histórica y dinámica, entonces, o no existe o es un mero engaño de masas. 